\title{
Challenges in Mixed Ability Classes and Strategies Utilized by ELI Teachers to Cope with Them
}

\author{
Muneerah S. Al-Subaiei ${ }^{1}$ \\ ${ }^{1}$ English Language Institute, King Abdulaziz University, Kingdom of Saudi Arabia \\ Correspondence: Muneerah S. Al-Subaiei, English Language Institute, King Abdulaziz University, Kingdom of \\ Saudi Arabia. E-mail: muneerahalshuraim@gmail.com
}

Received: March 1, 2017 Accepted: May 22, 2017 Online Published: May 29, 2017

doi: 10.5539/elt.v10n6p182 URL: http://doi.org/10.5539/elt.v10n6p182

\begin{abstract}
Mixed-ability classes have been found to be one of the greatest detriments to students learning at English language institutions (ELIs). There has been a growing concern over the impacts of the mixed-ability classes calling for a study aimed at suggesting solutions for this situation. This study involves thirty-three female EFL teachers who work in an English language institute (ELI) and their feedback was obtained via questionnaires which were distributed online. The questionnaires addressed this issue on various levels following categories such as teaching and learning, materials, motivation and class management practices. The results indicated that the frequency of the cases of challenges in the teaching of mixed-ability classes was high and thus requiring appropriate solutions. Class management and differentiation strategies were found to be the most effective in mitigating the adverse effects which mixed-learning abilities have on learning successes. The effectiveness of the strategies used had no relation whatsoever to the level of experience of the teachers. Strategies that seem to work best were those that focused on the students or what is referred to as student-centered approach.
\end{abstract}

Keywords: Mixed-ability classes, strategies, challenges, English Language Institute (ELI), Saudi Arabia

\section{Introduction}

Among the many challenges facing teaching instructors today is the mixed-ability class. According to Chapman and King (2003), a mixed-ability classroom consists of a group of students with differing levels of learning abilities, interest, and skills. EFL teachers have grown to identify this as one of the greatest aspects that invariably determines the level of teaching and understanding of what the students undergo in the long run. In support of this, Hedge (2000) noted that teaching a classroom of mixed-ability students is a vital and genuine issue that instructors experienced daily. He also went on to reckon that the mixed-ability problem demanded serious attention from experts in the educational field. While each learner has their own unique way of learning English coupled with different linguistic knowledge and the individual pace of learning; there seems to be an overarching need for the instructor to apply methods that would engage all the students in the same measure. This is especially because a dilemma normally arises for the instructor on who to concentrate on. Should they concentrate on the advanced learners and neglect the weaker ones? The converse of this would also be disadvantageous to the advanced learners, since they will not be able to participate based on their true potential. Following this situation, this study attempts to explore the challenges of mixed-ability classes and strategies that are utilized by EFL teachers to overcome these matters.

\section{Literature Review}

Mixed-ability classes generally refer to classes where learners have a broad range of levels in their achievement and learning. The students in these classes differ in strengths and weaknesses and have different approaches to learning. Different scholars have defined this topic in many ways using the different perspectives gained from different learning environments. Ansari (2013) for instance describes a mixed-ability class as comprising of not only learners with various capacities but also those that have a broad range of preferences and learning styles. They can also be referred to as a variation of students in their abilities in grammatical knowledge, fluency and accuracy, size of vocabulary, receptive and productive skills (Valentic, 2005).

Notably, there are many factors which may differ from one student to another such as their attitude, motivation, and self-discipline (Lightbown \& Spada, 2006). This makes it difficult for the teachers to effectively plan for 
their lessons to ensure that all their students reap the required benefits from the lesson. This is especially a challenge for the language instructors who are not equipped with the required skills and teaching methods to deal with mixed-ability classes (Ansari, 2103). Most institutions have sorted to address this problem by dividing the classes according to their ages. But these classes are still multileveled since it is still deemed random when individual abilities are considered. Studies have shown that random grouping does not incorporate the level of ability and attainment skills of individual students. This results in various challenges to the teachers who try to give equal opportunities for learning to all the students in the class (Boaler, 2008).

However, there are advantages associated with teaching in mixed-ability classes even though they are often overshadowed by the challenges. These classes provide interesting learning environments because they are composed of a rich pool of diverse skills, dispositions and perspectives. Most importantly, the interactions in these classes enable the students to be more creative and innovative as they learn from each other's unique abilities. However, the difficulties faced by language instructors in mixed-ability classes are often numerous and invariably lead to frustrations on their part since they are unable to create a productive learning and teaching environment for their students. Ireson \& Hallam (2001) suggest that instructors need to recognize that a class is of mixed-ability because learners have different strengths and weaknesses and improve at different rates. Consequently, instructors in regular classrooms are always put under intense pressure to address the needs of their diverse learners (Mayer, 2008).

Teachers are also faced with the shortage of training programs and strategies to prepare them for such situations at the workplace. These strategies have been floated to be very crucial and instrumental in ensuring there is success in the learning experiences of the students. The fact of the matter is that most instructors lack the professional development, planning time, or the capacity to consistently implement differentiation (Loiacono \& Allen, 2008). Instructors in mixed-ability classrooms need to be afforded continuous training to better manage the challenges of their diverse learners (Butterworth, 2010).

Most classes are comprised of a large number of students, and it is the responsibility of the teacher to control the students and to deliver the lesson effectively. Since the responsibility of taking care of the individual needs of each student lies on the shoulder of a single teacher, it has become a very tedious process. It has become difficult to administer their lesson plans in a mixed-ability class since every student has a different level of understanding (Northcote 2006). A good example is seen when a teacher is explaining a concept in class. The students with a high-ability of understanding get bored as the instructor tries to make further explanations to the students with moderate to low levels of knowledge absorbing capabilities. The most challenging part of English language teaching in a mixed-ability class is the fact that the teachers are expected to guide students at their individual pace, regardless of the proficiency differences. Failure by the teacher to address the needs of every student often makes the active students maintain their active state whilst their more passive counterparts remain passive, with no positive development (Hedge, 2000). There is always a huge disconnection between these two types of students and thus, no progress in learning is recorded. This means that the teacher should employ different teaching methods and techniques to meet each individual student's needs; this is a challenging task, as it is usually not practical, especially with large numbers of students to handle. In most cases, the teachers turn to employing average teaching methods in a bid to achieve a healthy balance in the middle ground. This leaves the slow learners struggling while the academically advanced students get lost since the learning process effectively neglects their needs (Winebrenner, 2001). Moreover, other research suggested that all learners, including those recognized as gifted, need educational experiences that help them achieve their maximum potential (Burney, 2008; VanTassel-Baska, 2005) Teaching gifted learners in a diverse-classroom has revealed success, but is not consistent in having all learning abilities involved (Tyler, 2006).

There are several strategies that influence teachers in mixed-ability classes to think in a different way to help their students attain academic success. These strategies are also meant to help them cope with the many challenges they face. The recommended strategy for addressing teaching in a diverse-classroom is differentiation. This strategy has grown in status becoming a recurring theme in classroom instructional strategies (Tomlinson \& McTighe, 2006; Winebrenner, 2001). Instructors can divide their pupils into various groups, incorporating different student-centered methods to improve on their study and to motivate them to participate more in their preferred learning method. Some of the student-centered methods include; game competition, in-class activities, extra homework, and dramatization (Pedersen \& Kronborg 2014). To help address the challenges in mixed-ability classes, the teachers should incorporate other strategies like open-ended plans, contingency plans, appeal to all senses, self-access centers, and personalized tasks to their teaching methods. To enhance the effectiveness in the teaching of language in these classes, there should be good management of classroom activity coupled with effectiveness of presentation and the use of teaching aids such as audio-visual material in 
the learning process.

In addition, teachers should also be involved in the training programs and equipped with the ideal leadership skills to help them deal with any challenging situations that arise in their learning environments. To further empower them, they should be equipped with the relevant knowledge to better their understanding of the different abilities and needs of their students (Boaler, 2008). This will help them to use effective strategies in the classrooms to create a thriving learning environment that satisfies the needs of all learners giving them unforgettable learning experiences. The use of all these strategies will help increase student interest and help the teachers to identify the individual weaknesses of each student to assist them accordingly. Tomlinson (2001) suggests that teachers only need to differentiate instruction types in diverse-classrooms to strike a healthy balance and enhance the learning process.

To the best of the researcher's knowledge, no previous research studies have addressed this issue in the Saudi context. Such a gap is evident when searching the literature, and this study aims at filling this gap by conducting this study in Saudi Arabia.

\section{Research Questions}

The study was guided by the following three essential research questions:

1) What are the challenges encountered by ELI instructors in mixed-ability classrooms?

2) What strategies do ELI instructors practice to handle these challenges?

3) Is there a relationship between the strategies that instructors use to overcome the challenges and their years of experience in teaching?

\section{Methodology}

\subsection{Participants and Study Instruments}

The participants of this study involved 30 female ELI teachers, who teach students of different proficiency levels, at King Abdul-Aziz University in the academic year 2016/2017. The questionnaires were made available online and distributed by email. This study adapted a questionnaire from Al-Shammakhil and Al-Humaidi (2015). The validity of the questionnaire was checked following standards held by different experts from different colleges (Al-Shammakhil \& Al-Humaidi, 2015).

To obtain the nexessary data, a 5-point Likert scale of the questionnaire (available in the appendix) was sent to different ELI teachers who were requested to voluntarily participate by fillin in the online questionnaire. Thirty-three EFL female teachers' participants responded and their responses were used in the concluding data analysis.

The purpose of the questionnaire was to determine the challenges which teachers may have faced in mixed ability classes. In addition to this, the questionnaires were also tailored to acquire the crucial information regarding the strategies used by the teachers to cope with those challenges. The last element of information that the questionnaire sought to find out, was the level of training these teachers had undergone to cope specifically with these challenges. Since the study was conducted on a relatively smaller scale, a modified version of the questionnaire was used. The original questionnaire was tweaked to suit the requirements of this study with certain aspects of the questionnaire being excluded but keeping the relevant parts intact.

The questionnaire consisted of four categories, each covering different items which were in the long run interlinked with the learning environment of the students. These included teaching and learning, motivation, materials and classroom management.

\subsection{Ethical Considerations \& Study Procedures}

To conduct this study, an ethical approval from the ELI had been attained in the preparation or preliminary stages of the study. A cover sheet that explicitly showing the permission, the aims and the guidelines of the study were then attached to the questionnaires that were sent out. The questionnaires were labeled appropriately to indicate that the respondents could respond at their own volition, and that the study would be crucial for a research that would seek to achieve the improvement of the education sector.

\subsection{Data Analysis}

The statistics data processed and interpreted by an expert statistician through the use of IBM SPSS Statistics software package. 


\section{Results \& Discussion}

Question 1: How often do ELI teachers face challenges in mixed-ability classes?

This first construct item in the questionnaire aimed at quantifying the cases of challenges faced by the teachers in their quest to teach in mixed-ability classes. The first part was specifically meant to cover the first three categories mentioned in the methodology. These included teaching and learning, motivation and materials. In essence, this section of the questionnaire was focusing on the class environment such as the teacher's teaching methods and the student's reaction to these methods such as how motivated they were. The results indicated the mean and standard deviations of the challenges encountered by instructors in dealing with mixed-ability students. These results were divided into the following categories as below in Table 1 .

Table 1. Mean and standard deviations of the challenges faced by ELI instructors in mixed-ability classes

\begin{tabular}{lll}
\hline Category & Instructors & \\
\hline Teaching and Learning & Mean & Std. D \\
Motivation & 3.10 & 0.47 \\
Materials & 3.12 & 0.62 \\
ALL & 2.82 & 0.65 \\
\hline
\end{tabular}

Table 1 illustrates that teachers face various challenges in mixed-ability classes. This is shown with the above average overall mean value of (3.02) out of a total of (5). Teaching and learning challenges are the most frequent challenges instructors face with a mean value of (3.10). Challenges related to motivation follow with a mean of (3.12), while challenges in material use are on the third place with a mean value of (2.82). The results suggest that the teaching and learning, and motivation categories comprise of a greater share of the problems faced by instructors.

From these findings, it appears that ELI, EFL teachers experience different challenges in mixed-ability classes. These results are in line with those of previous studies that have indicated the difficulties encountered by teachers in teaching mixed-ability classes. Teachers of multi-diverse classrooms struggle to meet their students' different abilities thus, the students vary in their attitudes, motivation and self-discipline. Consequently, teachers face some complications in designing proper lessons that could fit students' needs. This is because they might be lacking in the necessary skills set to teach their students better (Lightbown \& Spada, 2006). Continued training of teachers can reduce the amount of challenges they usually face (Butterworth, 2010).

Question 2: How often do ELI teachers use strategies to overcome these challenges?

This question was intended to address the classroom management practices employed by the teachers to mitigate the impact of the challenges they faced. The subject of classroom management was all-encompassing and required the respondents to give answers regarding the teaching and learning methods and classroom materials. The results obtained were tabulated as indicated below.

Table 2. Means and standard deviations of the strategies utilized by ELI instructors in mixed-ability classes

\begin{tabular}{lll}
\hline Category & Instructors & \\
\hline Classroom management & Mean & Std. D \\
Materials & 3.75 & 0.38 \\
Teaching and learning & 3.23 & 0.73 \\
ALL & 3.11 & 0.66 \\
\hline
\end{tabular}

Table 2 shows that teachers tend to use management strategies more than other strategies with a high mean value of (3.75), while the other two strategies have moderate mean values of (3.23) and (3.11). The findings confirm the idea of the teacher training necessity, as teachers who lack training could affect the students' proficiency. 
Teachers appear not to be aware enough of differentiation implements (Loiacono \& Allen, 2008). The previous result may be explained by the fact that ELI teachers could benefit from training courses and practicing different strategies with the students.

Turning now to address the third research question which aimed to explore to the relationship between the years of experience of the teachers and the management strategies they use to address the challenges they face in class. The results were also tabulated.

Table 3. Means and standard deviations of strategies practiced by teachers and their years of experience

\begin{tabular}{lllll}
\hline Category & Experience & $\mathbf{N}$ & Mean & Std. D \\
\hline \multirow{3}{*}{ Classroom management } & $0-1$ & 6 & 3.88 & 0.62 \\
& $1-5$ & 16 & 3.68 & 0.33 \\
Materials & $5+$ & 11 & 3.76 & 0.29 \\
& $0-1$ & 6 & 3.74 & 0.77 \\
Teaching and learning & $1-5$ & 16 & 3.01 & 0.70 \\
& $5+$ & 11 & 3.27 & 0.66 \\
& $0-1$ & 6 & 3.33 & 0.69 \\
\hline
\end{tabular}

From Table 3, it appears that there is no significant correlation between the strategies utilized by instructors and their years of teaching experience. The success rate of the management practices used, therefore, has nothing shared with teaching. Teachers would benefit the most when applying differentiated instruction to students (Tomlinson, 2001). This would help them settle with the practices which work best.

\section{Conclusion}

This study reveals that the mixed-ability students found in nearly all schools and classes present their teachers with marked difficulty in teaching effectively. Teachers are also noted to feel out of touch with students or not in control of the students when they post negatively unexpected results. These challenges require the instructors to employ effective management methods in addressing the said challenges. This can be achieved by using different methods in a bid to experiment with different strategies and settle on the most effective ones.

Apart from employing these management practices, it is paramount that instructors focus on the positive aspects of the classes. Teaching these classes can somehow be challenging due to the complexities involved, but mixed-ability classes are known for their diverse strengths. The instructors should subsequently focus more on these strengths. An appropriate method of doing this is by coming up with specific tasks for the various levels to keep the students always engaged, hence improve their learning capabilities.

Moreover, teachers who have a positive attitude towards the diversity in terms of student abilities are more successful in the teaching of mixed-ability classes. Planning for specific tasks of the various levels of ability of the students will ensure that all learners are engaged in the learning process and at personal levels and this, in turn, will ensure efficiency and success in the teaching of mixed-ability classes.

\section{References}

Al-Shammakhi, F., \& Al-Humaidi, S. (2015). Challenges facing EFL teachers in mixed ability classes and strategies used to overcome them. World Journal of English Language, 5(3), 33. https://doi.org/10.5430/wjel.v5n3p33

Ansari, M. S. (2013). Coping with the Problems of Mixed Ability Classes: A Study in the Context of Teaching English as SL/FL. International Journal of English: Literature, Language \& Skills.

Boaler, J. (2008). Promoting "Relational Equity" and High Mathematics Achievement Through an Innovative Mixed-Ability Approach. British Educational Research Journal, 34(2). https://doi.org/10.1080/01411920701532145

Burney, V. H. (2008). Applications of social cognitive theory to gifted education. Roeper Review, 30(2). 
https://doi.org/10.1080/02783190801955335

Butterworth, D. B. (2010). Placing Gifted Students At-Risk in Mixed-Ability Classrooms: A Sequential Mixed Methods Analysis. ProQuest LLC. 789 East Eisenhower Parkway, PO Box 1346, Ann Arbor, MI 48106.

Chapman, C., \& King, R. (2003). Differentiated instructional strategies for reading in the content areas. Thousand Oaks, CA: Corwin Press.

Hedge, T. (2000). Teaching and learning in the language classroom. Oxford, UK: Oxford University Press.

Ireson, J., \& Hallam, S. (2001). Ability grouping in education. Sage publications ltd.

Loiacono, V., \& Allen, B. (2008). Are Special Education Teachers Prepared to Teach the Increasing Number of Students Diagnosed with Autism? International Journal of Special Education, 23(2), 120-127.

Lightbown, P., \& Spada, N. M. (2006). How languages are learned. Oxford University Press, USA.

Meyer, E. J. (2008). Gendered harassment in secondary schools: Understanding teachers'(non) interventions. Gender and Education, 20(6), 555-570. https://doi.org/10.1080/09540250802213115

Northcote, R. (2006). Making Mixed Ability Language Classes Really Work - A Report on the 1996 LTANT Conference. Babel Victoria Then Melbourne Journal of Australian Federation of Modern Language Teachers, 31(3).

Pedersen, F., \& Kronborg, L. (2014). Challenging Secondary Teachers to Examine Beliefs and Pedagogy when Teaching Highly Able Students in Mixed-Ability Health Education Classes. Australasian Journal of Gifted Education, 23.

Tomlinson, C. A. (2001). How to differentiate instruction in mixed-ability classrooms. Alexandria, VA: ASCD.

Tomlinson, C. A., \& McTighe, J. (2006). Integrating differentiated instruction \& understanding by design: Connecting content and kids. Alexandria, VA: ASCD.

Tyler, K. M. (2006). A descriptive study of teacher perceptions of self-efficacy and differentiated classroom behaviors in working with gifted learners in Title I heterogeneous classrooms. Doctor of Philosophy, The Faculty of the School of Education, The College of William and Mary in Virginia.

VanTassel-Baska, J. (2005). Gifted programs and services: What are the non-negotiables? Theory into practice, 44(2). https://doi.org/10.1207/s15430421tip4402_3

Valentic, D. (2005). ELT in multi-level classes. Hupe Newsletter, 23.

Winebrenner, S. (2001). Teaching Gifted Kids in the Regular Classroom: Strategies and Techniques Every Teacher Can Use to Meet the Academic Needs of the Gifted and Talented. Revised, Expanded. Free Spirit Publishing Inc., 217 Fifth Ave., North, Suite 200, Minneapolis. 


\section{Appendix 1}

\section{Question1: How often do you face the following challenges?}

\section{Teaching and Learning:}

-Following the pacing guide does not help me to follow individual students.

-Many students are unable to communicate using English especially low achievers.

-There is a wide gap among students' levels in different skills.

-The course books' activities do not suit the different levels of the students.

-It is difficult to plan a balanced lesson that fits all students with their different abilities.

-I cannot satisfy the needs of all students.

\section{Motivation:}

-Lack of confidence with some students leads them not to communicate in class.

-Some students quickly lose interest as they have a very low language ability.

-Simplifying the lesson for low ability students decreases good students' interest.

-There is a lack of motivation among some students in the class.

-Low-level students feel they are treated unequally in mixed ability classes.

-It is difficult to ensure that all students are challenged and interested.

-High-level students feel they are treated unequally in mixed ability classes.

\section{Materials:}

-It is difficult to design different activities for different levels to achieve the same goal.

-Fixed lesson plans prevent us from adapting various activities.

-The teacher's book does not support me with effective strategies to deal with mixed ability classes.

-Course books are designed solely for average learners neglecting high and low achievers.

-It is difficult to find appropriate teaching resources for different levels.

-It is difficult for me to design or adapt different materials regularly.

\section{Question2: How often do you use the following strategies?}

\section{Classroom management:}

-Calling students by their names to make them feel respected and to pay attention.

-Involving high-level students in class management to save teacher's time.

-Varying voice to make the meaning clear and to get the students' attention.

-Giving students time to copy important information from the board.

-Working closely with low-level students to motivate them.

-Giving extra activities to the group or the students who finish earlier.

-Varying the pace and level of instructions.

- Using art and images to attract students' attention.

-Students sit in groups forming different shapes.

-Changing pairs from time to time.

-Personalizing tasks (students talk about themselves and their experiences).

-Assigning mixed-ability group project (students get different roles while working on the project).

-Using in-class peer-tutoring. 


\section{Materials:}

-Using simplified materials that are not demanding for low-level students.

-Using a bank of materials at the ELI with activities with different levels.

-Preparing handouts before the beginning of the semester.

-Adapting open-ended tasks (summary, analysis, express opinions).

-Applying Jigsaw activities (each student is doing a part).

-Using more communicative activities (games, puzzles, etc.)

-Using more authentic materials beside the course book.

\section{Teaching and learning:}

-Explaining the purpose of homework for the students.

-Regular class observations among teachers.

-Writing the aims of the lesson on the board regularly.

-Planning to observe 3 or 4 students every day while walking around the class.

-Applying creative tasks that allow students to work at their levels (story, opinion, diary).

-Designing vocabulary cards to improve reading ability.

-Summarizing the lesson with the students.

-Giving extra lessons for some students.

-Exchanging ideas with other teachers

-Teaching students the importance of note taking.

-Providing students with information gap activities

-Using different levels of stories and folktales.

-Encouraging students to reconstruct stories.

-Mixing compulsory with optional tasks.

-Applying multilevel dictation (blank sheet of paper, a medium level cloze and a cloze with only a few blanks).

-Having drama and sketch (miming, role play, etc.) in class to have a stress-free environment.

-Providing a menu of work for the students and they choose.

-Involving low-level students in English Club Activities.

\section{Copyrights}

Copyright for this article is retained by the author(s), with first publication rights granted to the journal.

This is an open-access article distributed under the terms and conditions of the Creative Commons Attribution license (http://creativecommons.org/licenses/by/4.0/). 